Document downloaded from:

http://hdl.handle.net/10251/92556

This paper must be cited as:

Ciarli, T.; Coad, A.; Rafols García, I. (2016). Quantitative analysis of technology futures: A review of techniques, uses and characteristics. Science and Public Policy. 43(5):630-645. doi:10.1093/scipol/scv059

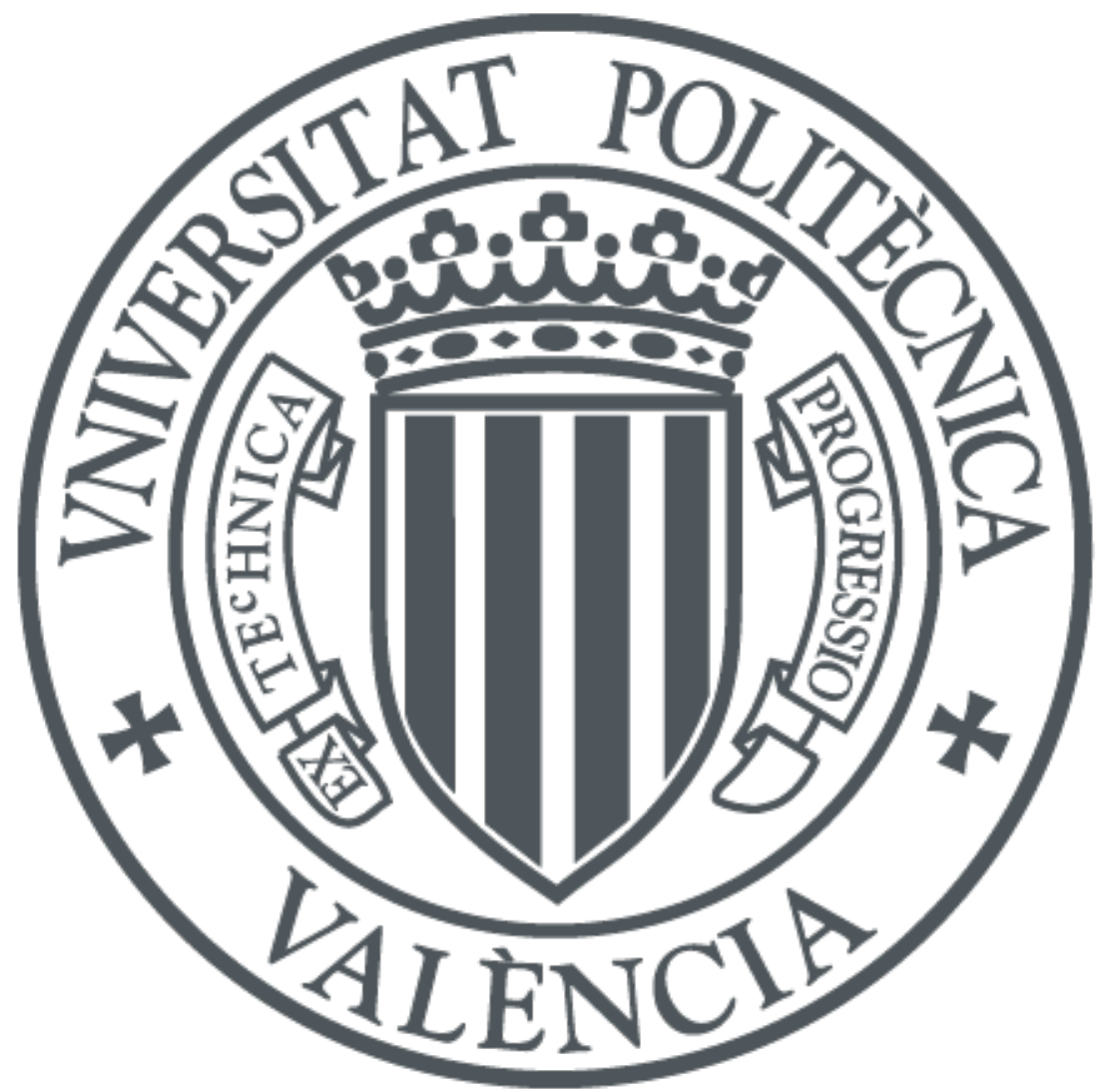

The final publication is available at

http://doi.org/10.1093/scipol/scv059

Copyright Oxford University Press

Additional Information 


\title{
Quantitative Analysis of Technology Futures: A review of Techniques, Uses and Characteristics ${ }^{\mathrm{a}}$
}

\author{
Tommaso Ciarli ${ }^{\dagger} \quad$ Alex Coad $^{\star} \quad$ Ismael Rafols $^{\diamond}$ \\ Preprint version of a paper forthcoming in Science and Public Policy
}

\begin{abstract}
A variety of quantitative techniques have been used in the past in FutureOriented Technology Analysis (FTA). In recent years, increased computational power and algorithms, web-based searching, and data availability have led to the emergence of new techniques that are potentially useful for foresight and forecasting. As a result, there is now a wide palette of techniques that might be used in FTA exercises. However, it is often unclear how they differ, when the use of a techniques is appropriate, what type of insights it may yield, and how they can be combined. This article reviews and qualifies quantitative methods for FTA in order to help users to make choices among alternative techniques, including new techniques that have not been integrated yet in the FTA literature and practice. We first provide a working definition of Future-Oriented Technology Analysis (FTA) and discuss its role, uses, and popularity over recent decades. Second, we select 22 FTA techniques identified as the most important quantitative FTA techniques and then we review these techniques, discuss their main contexts and uses, and classify them into groups with common characteristics, positioning them along four key dimensions: descriptive/prescriptive; extrapolative/normative; data gathering/inference; and forecasting/foresight.
\end{abstract}

Keywords: Future-oriented Technology Analysis (FTA); Quantitative Techniques; Foresight; Forecasting

JEL Codes: O3

\footnotetext{
"We have benefited from comments on a preliminary draft from Jessica Bland, Michael Hopkins, Ben Martin, Rafael Ramirez and Andy Stirling. We are indebted to Alan Porter for his thorough review, which helped improving the paper. We are grateful to an anonyous reviewers for insightful comments and to the SPP editor. All errors and omissions are our own responsibility. A first report form of this article was prepared as part of the project financed by NESTA on 'Research into the quantitative Analysis of Technology Futures'. We acknowledge further support from the US National Science Foundation (Award $\# 1064146$ - "Revealing Innovation Pathways: Hybrid Science Maps for Technology Assessment and Foresight"). The findings and observations contained in this paper are those of the authors, do not necessarily reflect the views of the National Science Foundation, and may not in any circumstances be regarded as stating an official position of the European Commission.

${ }^{\dagger}$ Corresponding author. SPRU, University of Sussex, UK. t.ciarli@sussex.ac.uk

¥JRC-IPTS, European Commission, Seville, SP. Alexander.COAD@ec.europa.eu

'Ingenio (CSIC-UPV), Universitat Politècnica València, València, SP; SPRU, University of Sussex, UK.i.rafols@ingenio.upv.es
} 


\section{Introduction}

Technological change is so pervasive that we have begun to regard it as a 'natural' and necessary phenomenon. However, technological change has had such an impact on the course of humanity, that it would be anomalous were we not to try to understand its sources and consequences of its impacts. Technological change cannot be taken for granted, and does not happen according to some 'natural' law particularly with respect to the directions it takes.

It follows that we need to understand the sources and impacts of technological change and its trajectories. Technological development is full of uncertainties, both in strategic direction and in unintended effects. First, the direction of technological change is influenced as much by apparently everyday choices as by strategic choices. In other words, the direction is in part the outcome of a large number of institutional factors, some of which visible and explicit, and others that may appear mundane (MacKenzie, 1998; Pinch and Bijker, 1984; Rip et al., eds, 1995). Overall, it does matter who influences decision on technological developments, and which horizon, goals, indicators and policies she uses to frame technology futures.

Second, small changes in technological events have an impact on the very distant future, precluding most historical paths with respect to others - namely with respect to the only one observed. For example, Diamond (1997) shows how small differences in initial endowments across the planet have strongly and irreversibly determined the shape and divisions of the modern world. On a smaller scale, a large number of studies have identified the sources of path dependence in technological choices, such as sunk costs, network externalities, architectural standards, economies of scale, and the irreversibility of investments. Probably the most famous example is David (1985), which shows that a series of historical accidents and encounters determined the so far unbeaten success of the QWERTY keyboard despite its lower efficiency with respect to alternative designs. Similarly, Arthur (1989) shows how, under given conditions, simple random buying decisions of identical consumers are sufficient to determine the pattern of a dominant technology between two that initially are identical, and determine lock-in to the winning product/technology. Cowan and Gunby (1996) analyse in depth how the choice of farmers, in a very short period, determined the supremacy of chemical pesticides at the expense of competing, socially superior, technologies such as Integrated Pest Management. In other words, the trajectory of technological change is determined in a way that is not reversible and that has dramatic consequences on the world in which we live.

In turn, both the political and social effects of a technology depend on the direction it takes. An early example is the analysis by the Club of Rome on energy and raw materials shortages, 
and the unsustainable environmental impact caused by the exponential patterns of growth in the industrialised economies (Meadows et al., 1972). More recent examples might be the free access to the Internet, which enables initiatives such as Wikipedia and knowledge sharing among all those with access to a computer, and the Internet. Other types of Internet developments might have led to paid access, as it is common for many medical technologies.

A large variety of qualitative and quantitative techniques are used to explore and analyse the future to forecast the direction of technological change and its effects on society, and to manage risk under changing uncertainties. For example, Porter et al. (2004) surveyed around 50 different FTA techniques around about half of which are based on quantitative analysis.

The analysis of the future has been mainly the prerogative of governments and large companies. Foresight activities can also influence future events, and shape technologies, social relations, and cultures. For instance, in early foresight activities - then called forecasting - in the 1960 s 'every society [...] is consciously committed to economic growth, to raising the standard of living of its people, and therefore to the planning, direction and control of social change' (Kahn and Wiener (1967), p. xxv, cited in Johnston (2008)). Following the 1974 oil crisis in particular, foresight diffused throughout the corporate sector (Johnston, 2008) but it was only during the 1990s, following the pioneering work of Irvine and Martin (Irvine and Martin, 1984; Martin and Irvine, 1989) and the foresight activities pioneered by the Japanese government, that technology foresight and forecasting became widespread activities attracting a large attention and investment from practitioners and academics.

Following the diffusion of FTA, a number of authors agreed that " $[\mathrm{e}]$ xploring the future should never be identified with forecasting. Whereas forecasting is founded on determinism, futures research encompasses a view of the world based on freedom of choice' (Fontela, undated, p. 8). Technology foresight and forecasting are only two of the ways we can explore future scenarios, i.e. two types of FTA (Porter, 2010). ${ }^{1}$ Here we use the abbreviation FTA to refer to analytical tools that allow to find suitable ways to study possible future scenarios that could shape social and economic conditions, and bring relative advantage. Where 'suitable' refers to the ability of FTA to provide an understanding of current conditions and problems, project them, and help the users think of changes to technology that fall near the event(s) intended or observed in the future and to the direction that technology should take to address pressing social and economic needs. FTA contains both positive and normative elements: some exercises are aimed at studying short and long term trends; others are aimed at deciding about which actions should be taken to engineer the course of the future.

\footnotetext{
${ }^{1}$ Foresight scholars now prefer to refer to Future-oriented Technology Analysis (FTA) rather than Technology(-oriented) Future Analysis (TFA) (Johnston, 2008), though the readers may find that TFA and FTA have been used as alternatives in the literature.
} 
In both cases FTA comprises a strong performative element: by imagining the future - and reading the present - FTA also creates the future. Referring back to the examples cited above, while computing possible disastrous world growth patterns (based on observable trends and a number of simplifying hypotheses), the Club of Rome provided a powerful imaginary of the future state of the world and the consequences of human activity (Forrester, 1971; Meadows et al., 1972), and in doing so had an effect on the behaviour of people and thus it changed the future. $^{2}$

The performative dimension of FTA means that the choice of techniques used in the FTA are likely to have not only an effect on the analysis but also in the development of the associated policies, technologies and contexts. However, in the face of a quick proliferation of analytical techniques associated with "Big data" (due to the increased computational power and algorithms, web-based searching, and data availability), decision makers find it difficult to know which FTA techniques are useful for which aspect and goals related to FTA exercises. In order to address this gap, the present article provides a reasoned review of (1) the literature on the different activities that are part of the large family of FTA, and (2) the quantitative techniques, tools, and methodologies available. The aim of this article is not to evaluate the different techniques and suggest which are 'best' in terms of their success/effectiveness (for this see, e.g. the chapter by Georghiou and Keenan (2008)). Instead, in the absence of any systematic way to compare different quantitative techniques (Scapolo and Miles, 2006; Eerola and Miles, 2011), the aim in this paper is to map the main strengths and weaknesses of the techniques traditionally used, and those that have yet to enter the FTA literature.

Different quantitative techniques serve different purposes and may be used under different policy circumstances. To provide a useful map of existing quantitative techniques, we first systematically select among FTA techniques. Next, we adapt the well-established categorisation suggested in Porter (2010) to distinguish between descriptive and prescriptive FTA exercises. Porter (2010) also analyses two different FTA activities along nine different dimensions. We argue that these dimensions can be generalised and employed to directly characterise FTA techniques. These characteristics are useful to delineate the strengths and weaknesses of different techniques, and how they may be employed in different FTA activities. We then map the main contexts and organisations in which techniques have been used, and how they represent knowledge about future outcomes and probabilities of events (Stirling and Scoones, 2009).

In this paper we thus answer questions such as: which quantitative techniques are more suitable in given contexts, and to investigate a given time horizon? Which techniques should policy makers use as complements, and under which circumstances? The availability of Big

\footnotetext{
${ }^{2}$ See for example Franzen (2010).
} 
Data has given way to the development of new techniques, which are not considered FTA, but which might be suited for FTA. On the one hand these techniques nurture the impression that a large number of people may be involved in decision making (or at least their revealed preferences) because information on them is made available. On the other hand, quantitative techniques are usually restricted to a small number of skilled analysts. We thus ask which techniques include the views of different stakeholders. We review the different techniques with respect to the breadth of inputs (e.g. types of data, issues considered), and the degree to which the outputs have the effect of 'opening up' associated policy debates on technology futures. In a different paper we provide a detailed discussions and assessment of FTA techniques based on these dimensions (Ciarli et al., 2013b).

The review provides the reader with a reasonably thorough understanding of (a) the strengths and weaknesses of most FTA quantitative techniques, including some recent techniques that emerged especially following the availability of Big Data, but which have yet to be integrated in the FTA literature and traditional practice; (b) the main contexts and organisations in which they are used; (c) their main drivers, and purposes for which they are best suited; (d) the time horizon considered; (e) whether they are used mainly for data gathering or inference, and how these two activities complement each other; and (f) how they represent knowledge about outcomes and the likelihood of events.

The main conclusion suggested by our analysis is that no quantitative technique is sufficient to run a FTA on its own, but that different techniques can be useful in different points of FTA processes. Policy makers should complement descriptive and data gathering techniques with prescriptive techniques that allow for more open inference than simple data extrapolation. Second, forecasting techniques can be used only for quite short time horizons. Third, the data used is crucial. No quantitative technique is well suited to account for a large number of views on future directions of technological change, including those using Big Data. When future development that have an impact on the society are at stake, policy makers should consider broader views than those available in the data, or that can be told by a small number of experts.

The article is organised as follows. The next section provides our working definition of FTA, which builds on the numerous definitions of different types of FTA. The following section reviews the large and complex literature on the different types of FTA. After a brief overview of the history of FTA and the debates around its significance, we review the main classifications proposed in the literature, and extract the list of quantitative techniques available. We also report on a number of techniques suitable for FTA that the literature has overlooked so far; some of these are in use particularly at the corporate level. Based on the population of techniques available, section 3 describes their selection. Finally, the section 4 summarises the techniques 
with respect to the several dimensions that define their suitability for different contexts and organisations.

\section{Future-oriented Technology Analysis}

\subsection{History of an idea: a working definition of FTA}

According to Eerola and Miles (2011) '[f]uture oriented technology analysis (FTA) is an umbrella term for a broad set of activities that facilitate decision-making and coordinated action, especially in science, technology and innovation policy-making. [...] Indeed, understanding the dynamics of technological change is just one part of a broader mandate' [p. 265] 'So, FTA has many faces and comes in many "flavours", drawing on many different research traditions and methods. Practically any source of insight into the dynamics of science and technology [...] can be utilised as knowledge inputs into FTA' [p. 267].

Thus, FTA includes a variety of related but different activities which Porter (2010, p 37) describes as "technology foresight", "technology forecasting", "technology intelligence", "technology roadmapping", and "technology assessment". Here, we refer mainly to foresight and forecasting, two activities sometimes considered synonymous, and sometimes seen as different, as we will see in the next section (Miles, 2010; Martin, 2010). ${ }^{3}$

Since its early phases the literature on FTA has taken off in different directions. Although technology foresight and forecasting activities often overlap, and the differences in definitions across various countries blur, we report here the main differences between the two. ${ }^{4}$

The fathers of technology foresight define it as 'the techniques, mechanisms and procedures for attempting to identify areas of basic research beginning to exhibit strategic potential' (Irvine and Martin, 1984, p. 7) where strategic potential refers to 'areas [...] that are beginning to show promise of constituting a knowledge base that, with further funding, might eventually contribute

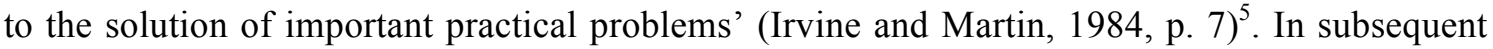

\footnotetext{
${ }^{3}$ There are also differences in the ways that foresight and forecasting are referred to in different parts of the world. Although following Irvine and Martin's introduction of foresight (technology foresight) most organisations adopted the term foresight rather than forecasting; in the USA, a number of activities that would be considered foresight activities in Europe, continued to be referred to as forecasting (Martin, 2010).

4 These definitions are based on FTA undergoing in Europe (starting with the UK), the US, and Japan. For a broader understanding we direct the interested reader to the NESTA report on foresight activities in developmental states (Ely et al., 2012).

${ }^{5}$ A contemporaneous similar definition is given in (Coates, 1985) (cited in Miles et al. (2008a)): 'a process by which one comes to a fuller understanding of the forces shaping the long-term future which should be taken into account in policy formulation, planning and decision making [...]Foresight includes qualitative and quantitative means for monitoring clues and indicators of evolving trends and developments' [p. 343]. This definition is in line with the main activities carried
} 
work Martin and Irvine (1989) add that foresight activity should influence the future development of technology: 'Foresight provides, at least in principle, a systematic mechanism for coping with complexity and interdependence as it affects long-term decision on research, in particular facilitating policy-making where integration of activities across several fields is vital' [p. 3]. In contrast, the need to engage with understanding and shaping future (technological) change is emphasised in the definition in Martin (1995): 'the process involved in systematically attempting to look into the longer-term future of science, technology, the economy and society with the aim of identifying the areas of strategic research and the emerging generic technologies likely to yield the greatest economic and social benefits' [p. 140].

The first definition (i.e. 1984's) focuses on basic research and does not refer to specific techniques, but to all activities that may contribute to the identification of science or technologies. The second definition (1995) encompasses more than basic research and includes a variety of future issues (not only technology) including broad economic and societal problems. While neither definition focuses on specific issues - 'important practical problems' in the first one and 'social and economic benefits' in the second - they refer implicitly to the role that technological change can play in improving the future human condition, which is expressed explicitly in the 1995 definition.

Foresight then is different from activities aimed at forecasting (i.e. predicting) future events and states of the world (Cuhls 2003). This is made clear in Miles et al. (2008a) 'the aim is not just to produce more insightful "future studies", more compelling scenarios, and more accurate econometric models. Foresight involves bringing together key agents of change and sources of knowledge, in order to develop strategic visions and anticipatory intelligence' [p. 11]. Technological forecasting is defined as "Ivory tower" future studies, in which an expert or consultant group produces its vision of the future or of alternative futures' (Miles et al., 2008a, p. 14).

To sum up, foresight should include the following elements (Miles et al., 2008a, p. 12):

(i) structured anticipation of needs (technology, society, etc.),

(ii) interaction of different stakeholders (in contrast to forecasting which uses only experts),

(iii) creation of a network of stakeholders with different expertise,

(iv) a strategic vision of the network of stakeholders,

(v) visions of the future, not utopia, that provide explicit implications for action and decision (policy),

out in the US and emphasises scanning and forecasting, not specifically related to science and technology (Miles et al., 2008a). 
(vi) communication among different disciplines, able to explain complex phenomena that rarely are partitioned into disciplines.

Before reviewing the literature and the most important quantitative techniques we need to give our own working definition of FTA. At its most basic, the idea of FTA is to provide analytical tools that allow the identification of 'suitable' ways to study possible future scenarios that could shape social and economic conditions, and provide relative advantage. 'Suitable' refers to the ability of FTA to help our understanding of current conditions and problems, project them into the future, and promote thinking about changes to technology that relate to potential future event(s) and to the direction that the technology should follow to address social and economic needs.

\subsection{Reviews on FTA}

Both technology foresight and forecasting exercises have employed a range of different quantitative and qualitative techniques which can differ in many dimensions, including their aims, aspects investigated, phase of the exercise, time horizon, organisation undertaking or commissioning the study, expertise and so on. In the next section we provide a classification of the different techniques along a number of dimensions. Here we review several systematisations and classifications of techniques, fitted within a number of dimensions provided by the literature.

Glenn and Gordon, eds (2003) (updated in Glenn and Gordon, eds, (2009), provide a useful guide to these techniques and their application, but does not offer a comparison among them. Indeed, it is not straightforward to compare among techniques (Scapolo and Miles, 2006) since it is necessary to make a number of simplifications about how they are applied, to what, by whom and for what purpose, in order to evaluate their contribution accurately. In this paper we attempt a meta-level comparison among different techniques with no claims that two techniques are directly commensurable. We aim to provide the reader not familiar with FTA with an idea of what is available, for what type of applications. An introduction to each of the techniques reviewed (with a description of its main features, its advantages and disadvantages, and examples of its use and associated references) is presented in Section 3.2 of Ciarli et al (2013a).

Porter et al. (2004) provide the first classification for a comprehensive list of quantitative and qualitative techniques - including Glenn and Gordon, eds (2003), categorizing them into families, distinguishing among those that, e.g. attempt purely creative exercises, from those 
aimed at providing point estimates of future developments of specific technologies. ${ }^{6}$ In between these two extremes (i.e. narrow prediction and sheer imaginative speculation) are techniques aimed at 'compiling information' and 'understanding interactions among events'. Although not all techniques are exclusive to a single family, this preliminary effort makes the significant contribution of relating techniques to different scopes such as time horizon, geographical extent and aggregation level. We return to these categories later.

Popper (2008a) provides two different classifications of foresight techniques - also divided into quantitative, qualitative and semi-quantitative - based on which phase they are likely to be applied, and as a function of the knowledge source.

We first examine his classification according to phase of usage. The literature and practice usually distinguish among different phases in an FTA exercise. With particular reference to technology foresight, Horton (1999), Miles (2002), Warden (2007) and Popper (2008b) suggest several classifications. All describe an initial phase when information and stakeholders are assembled: ${ }^{7}$ we refer to this as data gathering, and assume that the main outcome of the recruitment of experts serves the purpose of acquiring knowledge to be used in the FTA, in the form of qualitative or quantitative data. The second phase involves data elaboration to describe and visualise the current state (the type of exercise depends on the objectives of FTA) and elaborate scenarios or possible technology evolutions and states of the world. One expected result from this phase may be selection of the most likely or the most desirable futures: ${ }^{8}$ we refer to this as inference, assuming that all kinds of analysis in this phase, using any technique, will produce some understanding based on the evidence available (on the past) in order to infer with some degree of accuracy short or long run changes (in theory or in practice). The third phase consists of translating into action the outcome of the first two phases in ways that are relevant to a particular FTA exercise and organisation (e.g. publication, communication, policies, firm innovation). ${ }^{9}$

The second classification is based on the knowledge source, differentiating among techniques along two dimensions. The first is concerned more with data gathering activities and

6 The techniques are distributed across nine categories: Creativity, Descriptive and Matrices, Statistical, Expert Opinion, Monitoring and Intelligence, Modelling and Simulation, Scenarios, Trend Analyses, and Valuing/Decision/Economic.

${ }^{7}$ Following Horton (1999) the (i) collection, (ii) collation and (iii) summary of available information (trends, expected and unusual developments); also referred to as 'enactment' by Warden (2007) and as 'pre-foresight' by Miles (2002).

8 Following Horton (1999) the (iv) translation and (v) interpretation of knowledge acquired in the first phase to create understanding of its implications for the future of the organisation in question; also referred to as 'selection' by Warden (2007) and the 'generation phase' by Miles (2002).

9 Following Horton (1999) the (vi) assimilation and (vii) evaluation of the understanding (see above) to produce commitment to action in a particular organisation; also referred to as retention by Warden (2007) and as 'action phase' by Miles (2002), which may be followed by a 'renewal'. 
ranges from the consultation of a few experts to interaction with a large number of stakeholders. The second dimension is mainly concerned with inference activities and ranges from unstructured creative thinking to evidence-based techniques.

Given that our focus is solely on quantitative techniques, these two dimensions need to be adjusted, as follows. We consider 'expert' insights to be knowledge that can be applied to any phase in data gathering and inference. For example, expert knowledge can be used to interpret a statistical result or the visualisation of Big Data, and is not, as is often the case in the foresight literature and practice, the individuals that provide advice on particular aspects of a technology or issue (e.g. in a Delphi exercise). Similarly, in our classification, creativity is structured and may derive from the use of new techniques, such as social software, which so far have not been considered in the FTA literature. In other words, quantitative techniques can be used to exploit sources of creative information (i.e. blogs and social software), and as inputs to others' 'creative thinking', or to generate creative 'computing' with quantitative scenarios.

Bishop et al. (2007) focus on techniques used in scenario planning exercises, which are not very different from foresight exercises as defined by the authors. Apart from a useful list of advantages and disadvantages of the surveyed techniques, Bishop et al. (2007) contribution adds to the categorisations provided above in three respects. First, most techniques use actual data and information rather than assessments of current states, backcasting from plausible futures. Second, the vast majority of techniques (including qualitative) do not exploit computational power, which opens up a range of possible innovations in FTA. Third, according to Bishop et al. (2007), most techniques are of a very similar intermediate degree of difficulty, which should reduce bias in users' choices of a technique suited to a given scope.

We draw on two more surveys written by foresight practitioners, to build our classification of quantitative techniques. The first, Jackson (2011), is another summary of a selected number (26) of features of techniques. The second, Magruk (2011), provides a very comprehensive list of techniques. Magruk (2011), defines a large number of variables to characterise the listed FTA methods on the basis of references and personal experience in the field. He runs a cluster analysis and extracts ten categories. Although the categorisation method is interesting, the classification does not provide useful insights in the context of the current work.

Next, we list every technique mentioned at least once in the reviewed work. Eliminating obvious duplicates, this results in a list of 64 quantitative techniques. ${ }^{10}$ Some of these are partly overlapping; some differ or not according to different authors. All in all, it is quite a large number of available quantitative techniques, especially if we consider that the list does not

\footnotetext{
${ }^{10}$ Some techniques have both quantitative and qualitative aspects; we set a fairly high threshold for the quantitative content for a technique to be considered as quantitative, such that, e.g. Delphi methods are not included.
} 
include techniques used in some forms of FTA (in the comprehensive definition used here) that have not been included as FTA techniques in the academic literature. As we will see in more detail later (section 3.2), each technique has pros and cons, and can be classified according to a number of categories that define their use. So how are they chosen for a specific FTA? Does the literature inspire this choice or is it an outcome of different types of learning among the practitioners applying them?

All the contributions discussed so far (as well as our own contribution) use a classification based on a deductive method (i.e. they define the categories first and then attribute the FTA to a category) As far as we are aware, Popper (2008b) is one of the few inductive exercise (i.e. a study that classifies techniques according to their use in FTA practice) covering multiple countries and techniques, to understand which techniques are used in particular foresight exercises. ${ }^{11}$ Differently from the classifications discussed earlier, Popper (2008b) however focuses only on one FTA, foresight. Popper uses a database of 886 foresight exercises European Foresight Monitoring Network (EFMN Dynamo ${ }^{12}$ ) - to address the questions above: he looks at the main features of this sample of exercises collected by a number of practitioners and scholars of technology foresight over several years.

The database is part of a project run by EFMN and was constructed by volunteers from EFMN affiliates who contribute by including in the database foresight exercises which they get to know about. This sampling method is not particularly robust and many types of exercises and areas of the world are under-represented. However, it represents a rich source of information for an inductive understanding of the use of different techniques. The paper by Popper analyses how the choice of method is influenced by: (i) the nature of techniques - quantitative or qualitative; (ii) the capabilities - the ability to gather or process the information based on evidence, experts,

${ }^{11}$ An earlier study comparing foresight exercises over a number of features (Keenan et al, 2003) focussed on EU countries, and mapped a smaller sample (84 exercises); unfortunately we did not manage to access the data, and we could not find studies that analyse the data in a way similar to Popper (2008b). Other relevant inductive exercise, such as Cuhls (2008), were conducted in languages other than English, and could not be covered in this paper due to our own limitations. Grupp and Linsteon (1999) collect articles on national foresight activities comparing them with respect to their comprehensiveness, drivers (indsutry versus science), and purpose (analytic versus action oriented). Finally, a more focused comparison of Delphi and Cross Impact Analysis is found in Scapolo and Miles (2006). In this paper the authors run the same foresight exercise using the two different techniques and consulting the same experts, who then are able to judge which technique applies better to the specific case of the European transport system. Their first result is that the comparative exercise is extremely costly and difficult. Second, these techniques are not harmonised, thus the differences may be due to the way in which they are applied, not to the techniques themselves. Ultimately, there is no conclusive evidence on the most appropriate techniques (subjectivity in measuring the pros and cons): 'The techniques have somewhat different methodological principles, and may be intended to provide information for different purposes, though the literature is not so clear about what these are' (Scapolo and Miles, 2006, p. 700). To conclude, the choice remains related to the topic or sector as well as to the study scope or objectives.

12 http://ec.europa.eu/research/social-sciences/pdf/efmn-mappingforesight_en.pdf 
interaction among stakeholders, or creativity (see the classification in Popper (2008a)); (iii) the relative R\&D expenditure by region; (iv) the sector, industry, or research area covered; (v) the level of geographical aggregation; (vi) the time horizon; (vii) the actors funding the study; (viii) the types of organisations involved; (ix) the number of people involved; (x) the type of output generated - e.g. policy recommendations, scenarios, key technologies; and (xi) the number of methods used.

The results show that the choice of techniques differs according to their nature, geographical $R \& D$ intensity and use of different capabilities and techniques, but is insensitive to all other dimensions - particularly sectors, geographical aggregation, time horizon, funding organisations and target groups. In other words, and being cautious in the assessment of these data, analysis of a large number of foresight exercises shows no clear pattern for choice of techniques, suggesting that foresight practitioners, on average, do not consider the same techniques as being a better fit than some others, for particular types of exercises. In fact, much selection of techniques seems to be guided by intuition, impulse or lack of experience with the whole range of techniques (Popper, 2008b).

Eerola and Miles (2011) discuss a different problem related to the practice of FTA, which may be an explanation for the results in Popper (2008b): i.e. path dependence in the use of different techniques. '[A]necdotal evidence suggests that many FTA practitioners are simply reiterating the particular approaches with which they have been familiar for many years, with little acquisition of new approaches and little awareness of the costs, benefits and broader implications of alternative methods' (Eerola and Miles, 2011, p. 267). From a different literature - focused more on firm foresight (i.e. not necessarily technology) - Armstrong (2006) and Graefe and Armstrong (2011) suggest that most firms use non-structured face to face meetings as a forecasting tool, which can be expected to be biased compared to many other techniques (such as Delphi).

Ironically, the lack of comparison among techniques occurs in a field where its practitioners continuously question others about the best technologies for the future but do not question which technologies - or techniques - they should use to analyse the future: 'Thus the FTA field itself resembles many of the challenging problems, which are the subject of FTA analysis' (Eerola and Miles, 2011, p. 267).

The above evidence suggests that it is vital to have a comprehensive understanding of the available techniques, their main contexts of application, strengths and weaknesses, and information on the organisations that use them and find them useful. Even more crucial is the exploration and inclusion in the toolkit, of a number of quantitative techniques that have been recently used to analyse future trends, but which have not yet entered the FTA literature (see 
also Miles et al. (2008b)), e.g. social software, webometrics, altmetrics, Google trends, 'nowcasting', and correlate and prediction markets. We then quickly turn to investigating recent trends in the FTA literature and practice, comparing some of the traditional techniques with some of the most recent ones, not yet included in the FTA literature.

\subsection{Trends in FTA literature and practice}

A number of studies show that interest in FTA increased significantly in the 2000s (e.g. Porter, 2007). To see this we computed the number of articles published on FTA in the last few decades. We ran an exercise on the Web of Science (WoS) database ${ }^{13}$ searching for articles that contained one of the terms referring to FTA: 'technology forecasting', 'technology foresight', 'technology intelligence', 'technology roadmap', and 'technology assessment' (Porter, 2010). ${ }^{14}$

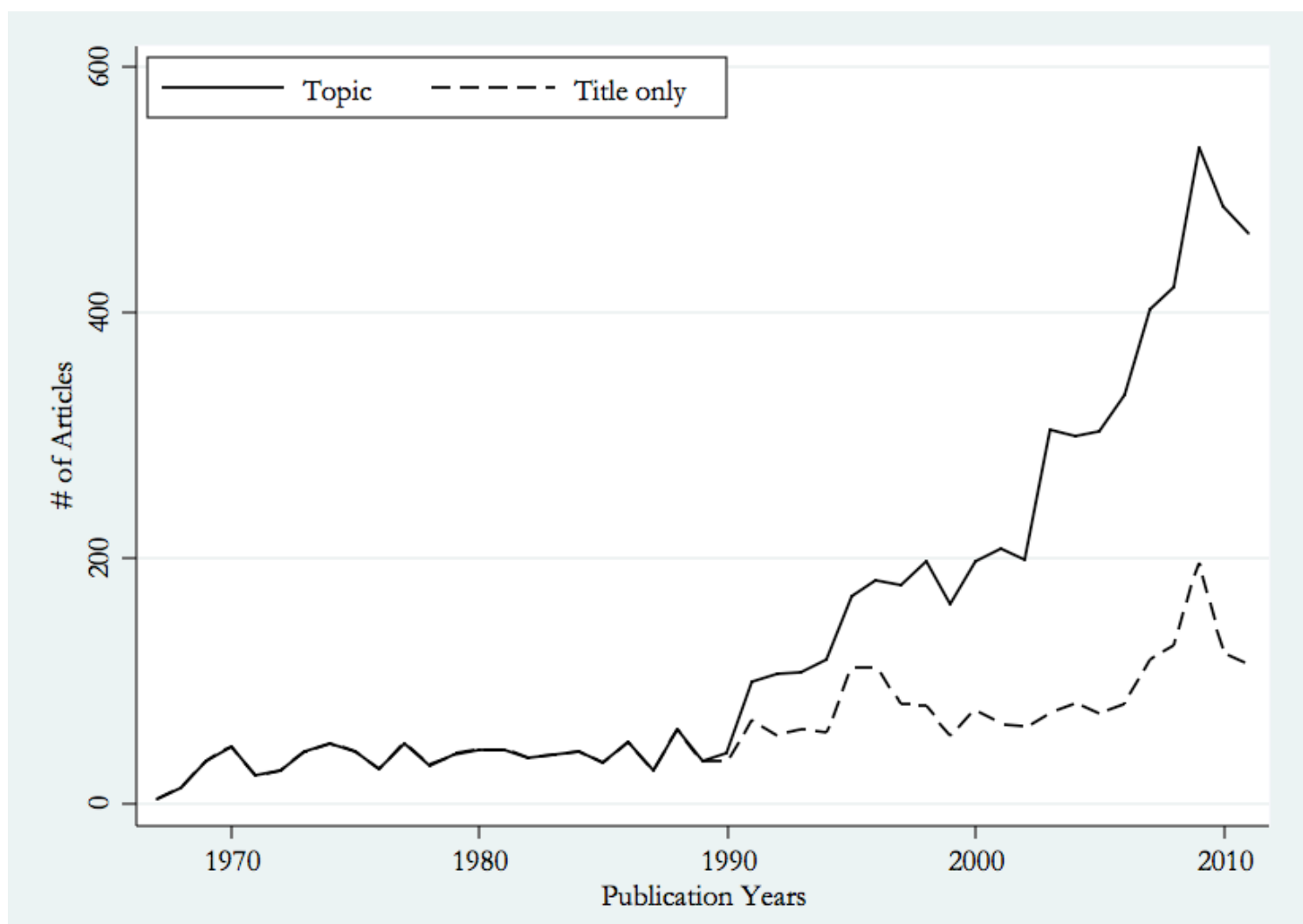

${ }^{13}$ See Porter (2007) for a discussion on the pros and cons of this choice in the case of this particular search.

${ }^{14}$ Our search string contained the following terms to capture the different forms of technology/technological and, e.g., forecast/forecasting: "technol*-forecast*" OR "technol*_ foresight*" OR "Technol*-intelligence" OR "Technol*-roadmap*" OR "Technol*-Assessment". The data were retrieved on the $7^{\text {th }}$ July 2012 for all document types using SCI-Expanded, SSCI, A\&HCI, CPCI-S, CPCI-SSH in the WoS. 
Figure 1: Number of articles published in Web of Science on Future Technology Analysis

between 1967 and 2011. The search includes one of the following strings: 'technology

forecasting', 'technology foresight', 'technology intelligence', 'technology roadmap', and 'technology assessment'. The solid line shows the results for keywords found in the abstract, keywords or title (introduced in WoS only since 1991); for consistency with the 1967-1990 dynamics, the dashed line shows the results searching only article titles

Figure 1 shows that the interest in the scientific, social sciences and humanities literatures those contained in the WoS - in FTA increased significantly at the beginning of the 1990s. This interest seems to have reached a plateau around the millennium, or a thoughtful pause, before showing quite dramatic growth starting in 2003. This finding is in line with the results presented in Porter (2007) for the period 1996-2006, which provides a more detailed analysis, disaggregating by the main FTA techniques, disciplines, sectors, journals and organisations. ${ }^{15}$ Even more interesting is the loss of momentum for the growing interest in FTA since 2008, with a new plateau at around 500 papers per year. Data on 2012 publications confirm this stagnation of interest. One explanation for this might be the financial crisis. There was a similar loss of interest in FTA in the early 1970s: initial growth was halted and did not recover until the early 1990s. This earlier reduced interest might be explained by the reduced confidence in foresight activities following the oil crisis. Similarly, the financial crisis and the inability of foresight activities to hint at its possibility, may have induced scholars and users of FTA to turn to different methods from those traditionally used.

To appreciate the relevance of the more recent techniques we analyse the relative weekly frequency of keyword searches in Google from 2004 - the year when the data were first collected - to 2012 using Google Insights. ${ }^{16}$ Figures 2 and 3 report the relative number of times that FTA activities were searched on, from any part of the world, in the eight years 2004-2012. In order to make the series comparable data are normalised (meaning that the figures reported here do not give information on the absolute number of Google searches).

\footnotetext{
${ }^{15}$ Results for 1996-2006 are available from the authors.

${ }^{16}$ Open access at http://www. google.com/insights. The query was last applied on 9 July 2012. As of 2013 Google insights has been integrated with Google Trends. In order to reproduce the results, the interested reader should therefore redo the following exercises in Google Trends http: / /www.google.com/trends/explore.
} 


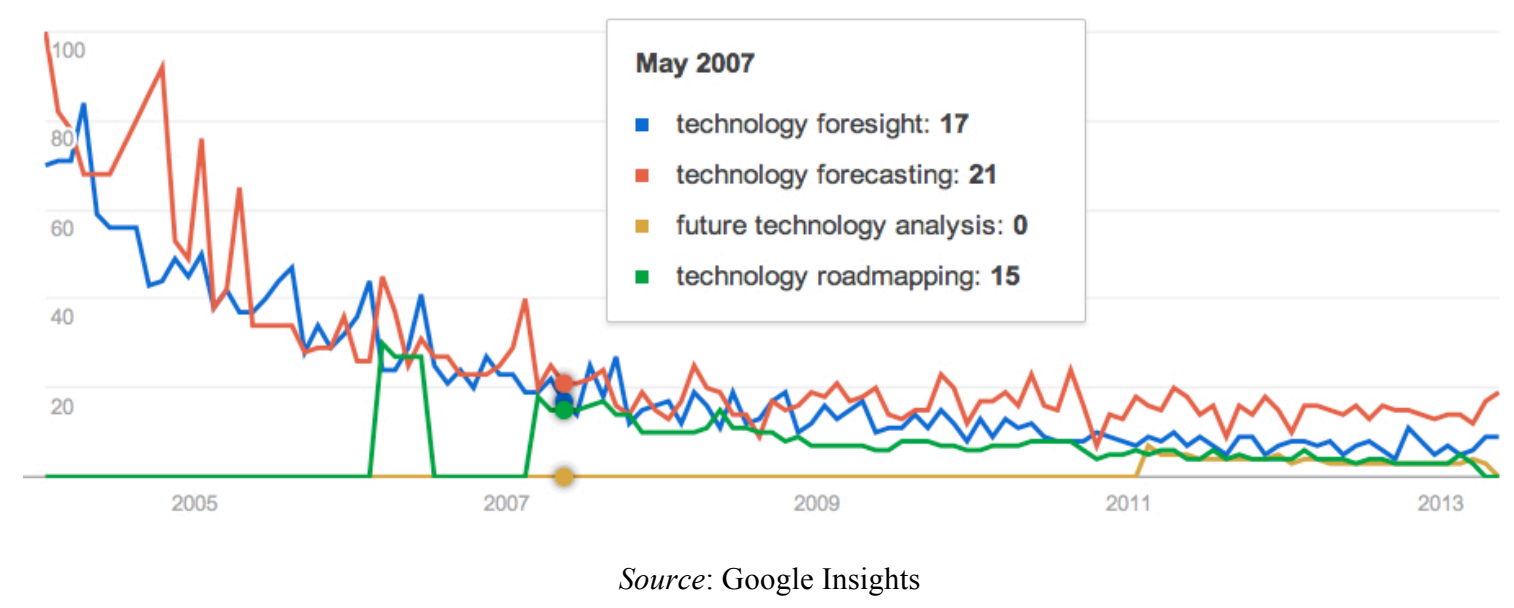

Figure 2: FTA traditional activities. Google search for Future Technology Analysis, Technology Roadmapping, Technology Foresight and Technology Forecasting, 2004-2012. On the vertical axis we plot the normalised frequency of the Google query of the term with respect to all other queries in the same period; on the horizontal axis we plot time

Figure 2 reports the results of searches for some of the most commonly-used FTA: Future Technology Analysis, Technology Roadmapping, Technology Foresight and Technology Forecasting. The figure indicates that since 2004 there has been a steady reduction in the relative number of web searches for FTA activities. This contrasts with the evidence for academic publications (Figure 1), which shows an increase from 2004, with stagnation occurring only after $2008 .{ }^{17}$ This difference may be due to a number of reasons, such as, the increased number of publications reduces the need for web searches, or web information precedes academic publications, ${ }^{18}$ or because FTA users are moving to different techniques and look for them using different keywords from foresight and forecasting.

The first explanation implies a causal relation between the availability of academic publications (normally not accessible for free) and the acquisition of knowledge by the community involved with FTA exercises (at firm, government or supranational level).

The second explanation implies that the academic community is realising with a 4 year lag, a reduction in interest in FTA activities, which is when publications growth stalls.

\footnotetext{
${ }^{17}$ Note that the data in these two figures are not comparable in quantitative terms. What we compare here are trends, not absolutevalues.

${ }^{18}$ A phenomenon observed by researchers in several fields, particularly with reference to the high cost and slow pace of academic publication compared to the free and almost immediately usable online resources.
} 
The third explanation implies that either there has been a change in terminology, such that academics and users do not use the same keywords to refer to FTA, or that users (in particular consultants) are searching for tools not part of the FTA terminology. We cannot say which explanation best fits the real dynamics, which may result from a combination of reasons. For example, there is a body of material published on more traditional FTA, but little is available in books or guides on the new tools; therefore, users may use academic references for the former and the web for the latter. Aaltonen and Sanders (2006) comments on this in reviewing the Futures Research Methodology - v2.0 (Glenn and Gordon, eds, 2003): they suggest that we need new (qualitative and quantitative) methods that allow analysis of complex, non-linear relations able to include new conditions and system's criticality: 'When we look at the rest of the methods [excluding SOFI and causal layered analysis], we find out that over four-fifths of them were invented in the 1970s or before' (Aaltonen and Sanders, 2006, p. 30).

In figure 3 we compare the two most common activities in FTA - technology foresight and technology forecasting, - with two widely used new tools - webometrics (a very general term including social software) and prediction markets. The figure shows that non-traditional tools are more frequent search keywords than traditional activities. In addition, webometrics shows an increasing path even when the spikes are smoothed. ${ }^{19}$ Finally, at the beginning of the financial crisis there has been a strong increase in searches for prediction markets, but not for FTA activities. This evidence might reflect disaffection with FTA similar to what occurred in the early 1970s after the oil crisis or may, as some experts in FTA suggest, indicate that new users, such as consultants, feel that new techniques that use huge datasets made available by the use of the Internet are more promising (or fashionable). We need to emphasise again that these comparisons are tentative, since neither Web of Science nor Google evidence constitutes robust evidence of the trends and it is not possible to conduct statistical comparison of series from these two different sources. Therefore, the results presented should be understood as being thought provoking and drawing attention to a phenomenon. ${ }^{20}$ Similar evidence, though, led to some analysts like Boden et al. (2012, p. 136) to state that 'there is a desperate need for new tools, for experimenting different application and combination of existing tools and aligning them to governance systems, to address the complexity of the grand challenges'.

\footnotetext{
${ }^{19}$ The spikes in February and August are due to the fact that the term 'webometrics' is also a university ranking website. However, the results change very little if we search on 'social software', and show an exponential increase if we use the keyword 'Big Data'.

${ }^{20}$ Note that if we add the word 'technology' to the new tools keyword search, replacing, e.g. 'webometrics' with 'technology social software', Google Trend data show that figures are low with respect to FTA, but that keyword searches start in 2007 and increase. Similarly, for prediction markets we were unable to find any exercise or document using prediction markets for technology futures.
} 


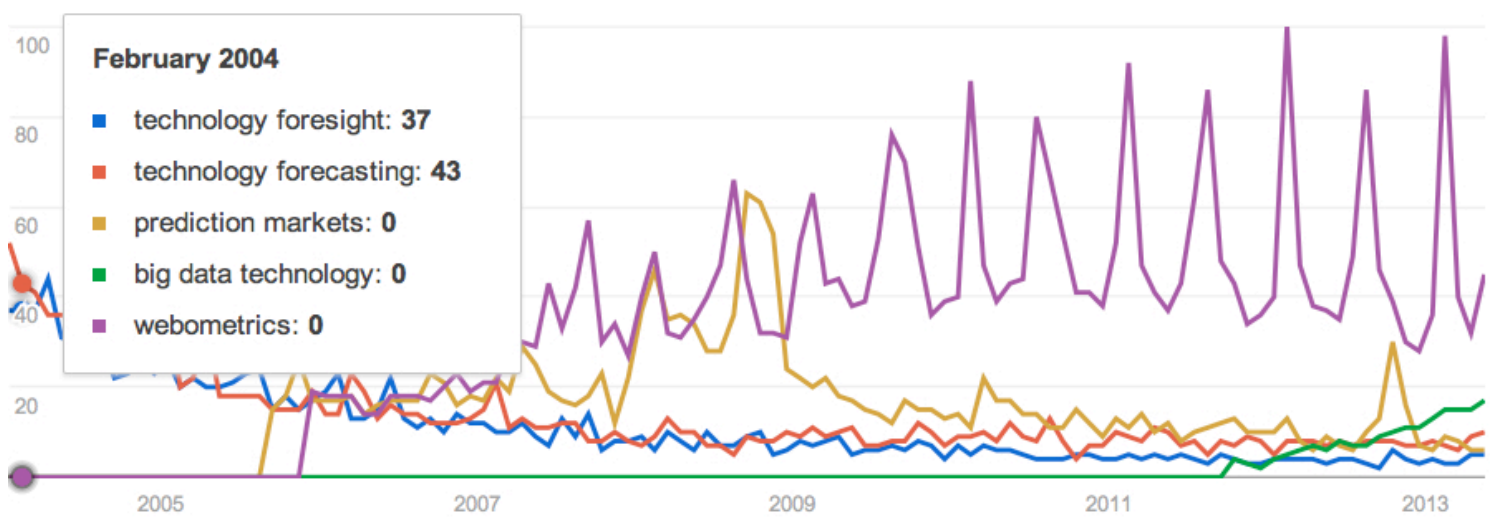

Source: Google Insights

Figure 3: Google search for Foresight, Forecast, Prediction markets and Webometrics. On the vertical axis we plot the normalised frequency of the Google query of the term with respect to all other queries in the same period; on the horizontal axis we plot time (2004-2012).

\section{Mapping FTA techniques}

\subsection{The selection of FTA quantitative techniques}

In this paper, we adopted the following procedure to select the most important quantitative techniques used in FTA. First, we build a list of all techniques that can be found in the literature, using: (i) the sources discussed in Section 2.2, i.e., in the order in which they are discussed there, Glenn and Gordon, eds (2009), Porter et al. (2004), Popper et al. (2008a), Bishop et al. (2007), Jackson (2011), and Magruk (2011); and (ii) the European Commission (EC) Joint Research Centre (JRC) ForLearn website. ${ }^{21}$ As a result we obtain a comprehensive list of 64 quantitative techniques.

Second, in order to select the most relevant techniques, we built the following six different indicators of relevance for each of the 64 techniques: (i) relevance in practice: the number of studies using the techniques according to the EFNM Dynamo data (Popper, 2008b); (ii) relevance in science: the number of publications with the name of the technique in the title, abstract or keywords available in Web of Science (WoS); (iii) relevance in science: the number of citations to these papers in WoS (the data were retrieved on the $7^{\text {th }}$ July 2012 for all document types using SCI-Expanded, SSCI, A\&HCI, CPCI-S, CPCI-SSH in the WoS); (iv) relevance in

\footnotetext{
${ }^{21}$ http://forlearn.jrc.ec.europa.eu/guide/4\_methodology/methods.htm accessed 3 June 2012.
} 
the grey literature: the number of results in Google scholar containing the name of the technique (in quotation marks); (v) relevance in popular interest: number of results in Google (in quotation marks); ${ }^{22}$ and (vi) relevance in surveys: the number of times the technique was mentioned or described in the six references written for practitioners cited above and discussed in Section 2.2.

Third, we made a logarithmic transformation of indicators $\mathrm{i}-\mathrm{v}$ to make the figures comparable. Fourth, given the low levels of correlation between some of these six indicators, we computed their sum to obtain an overall proxy for the relative importance of each technique: Sum. For instance, some techniques may be more relevant in the practitioners' world, while others may be more relevant in academia; some may be more widely discussed in journals, while others may be more popular in reports that are not published in scholarly journals. The sum is the best way to be as comprehensive as possible with respect to all techniques, being quite agnostic on the reason for their relevance (no weights were used).

Fifth, all techniques were ranked with respect to Sum, and the main techniques were selected according to their score, correcting for the following three criteria: (1) they should be mainly quantitative (some techniques are mixed); (2) the high Sum score does not depend on the name of the technique capturing something different from FTA (e.g. Analogies and Causal models); and (3) analyst's judgment from an extensive reading of the FTA literature.

Sixth, we grouped some of the techniques under a common term: different contributions ascribe different names to very similar, if not identical, techniques. For example, Complex Adaptive Systems (Porter et al., 2004), Modelling and Simulations (Magruk, 2011), and Decision Modelling (Bishop et al., 2007) were considered as variations of Agent Modelling (Porter et al., 2004). ${ }^{23}$ This procedure resulted in 22 techniques (See Appendix A), ${ }^{24}$ to which we added 4 new techniques not found in the several reviews analysed above: Social Software - which includes Webometrics and Altmetrics, Google tools such as Google Trends and Google Correlate, Prediction Markets, and Scenario Discovery - based on Robust Decision Modelling.

Selecting the most used, discussed, and published techniques may leave out some techniques that are extremely relevant to some niche FTA practices, or which are highly used only in particular countries (in particular given the strong English bias in social science coverage in the

\footnotetext{
${ }^{22}$ Results for both Google Scholar and Google were retrieved on the 9 and 10 June 2012.

${ }^{23}$ While Robust Decision Making (Glenn and Gordon, eds, 2009) has many common features with Agent Modelling, we believe it is more appropriate to consider it a Scenario technique.

${ }^{24}$ Eleven potentially relevant quantitative techniques were not selected, mainly because they referred to methods perceived as being general quantitative approaches rather than specific FTA methods (See Appendix A). Moreover, as a result of preliminary analysis of the selected techniques we decided to drop four of the techniques initially selected. Key Technologies was not retained because we could find no reference to quantitative techniques, and thus relabelled it a qualitative technique. Force Field Analysis was dropped because all the references found referred to organisational change, which is far removed from FTA. Structural analysis and Content analysis were dropped because they were perceived as too general.
} 
WoS). Although this is certainly a limitation, the selection is useful to create relatively homogenous families of techniques, and to compare them. Moreover, the selection method used is likely to favor the techniques with a longer tradition, against more recent ones. We have addressed this potential bias by using our own judgment in the final selection, and by including recent techniques that use Big Data, and which are not covered by the FTA literature and practice.

In Section 3.2 we group the resulting 26 techniques into ten families and discuss differences and similarities in their key characteristics as FTA tools. In Ciarli et al (2013b, Sec 3.2) we provide a description of each family of techniques; for brevity we describe families of techniques and add some details only for those techniques most representative of a family, if they add significantly different characteristics, or if they are new to FTA.

\subsection{Criteria for classifying FTA techniques}

Commonly used FTA quantitative techniques have different advantages and disadvantages. Some require different types and sources of data from others; some are more labour intensive or more difficult to operationalise. These quantitative techniques differ also in the extent of subjective judgement required, the amount of information collected from a number of experts or other stakeholders, or the ability to integrate with other quantitative or qualitative techniques in an overall FTA activity. Some techniques have been in use for a number of years and have been refined; others have not been sufficiently tested. These differences, in some cases, are due to the fact that the use of FTA techniques is subject to fads and path dependency (Popper, 2008b; Eerola and Miles, 2011). Moreover, there is a continuous flow of new techniques developed or borrowed from other disciplines. Some of the recent techniques have been included in the FTA practice to a limited extent - e.g. Robust Decision Making (RDM) (Lempert et al., 2009), hot topics bibliometrics and patents (e.g. Robinson et al., 2011), new applications of Input Output modelling (e.g. Wilting et al., 2008), and prediction markets (Wolfers and Zitzewitz, 2009). Others - such as various forms of social software, social networks, and Google tools - are widely used in FTA-related activities, but have so far received little attention from the FTA community in reports or academic articles. ${ }^{25}$

In what follows, we first cluster the 26 techniques in the following ten families (Porter et al., 2004; Porter, 2010): 'Creative', 'Monitoring and intelligence', 'Descriptive and matrices', 'Statistical methods', 'Trends analysis', 'Economic methods', 'Modelling and simulations', 'Roadmapping', 'Scenarios' and 'Valuing/Decision' (see Table 1 below).

\footnotetext{
${ }^{25}$ Recent exceptions are Cachia et al. (2007) on social networks, Nugroho and Saritas (2009) on social network analysis (SNA) and Pang (2010) on choice architecture.
} 
Second, following the well-established and comprehensive review by Porter (2010), we classify the ten families according to their uses. We distinguish four different uses: first we order the techniques from more descriptive towards more prescriptive; second, following this ordering we classify techniques also on the basis of whether they are mainly used for data gathering or for inference; third, we provide a first assessment of the features of the techniques and their use (advantages and disadvantages) moving from those that are more aligned to extrapolative exercises, to those more appropriate for providing normative insights; finally, with respect to the distinction often discussed in the literature between foresight and forecasting (see e.g. Miles et al., 2008a), we propose that the ordering followed here moves from those techniques more suited to foresight activities to those more suited to forecasting, to return to the foresight-geared techniques at the end of the spectrum (see Table 2).

Third, we review and classify the advantages (pros) and disadvantages (cons) of techniques, and their appropriateness for different contexts and organisations by assigning to the different groups and techniques the following five characteristics (Porter, 2010, Tab. 10): 'Drivers' science (research), technology (development) and innovation context (problem solving); 'Locus' - company, institution, sector, country/region and global; 'Time horizon' - short, mid range or long; 'Purpose' - informational and action-oriented; and 'Participation' - narrow, intermediate or representative process. The dimension 'Participation' refers to the range of different stakeholders that participate in the FTA process. We extrapolate its meaning by considering the breadth of stakeholder perspectives that are included in the FTA, even if this is not direct " participation', but mere use of text mining techniques aimed at capturing the views of diverse stakeholders.

Finally, we categorise the ten families of techniques according to how they are perceived to modify the appreciation of knowledge about the relevant 'outcomes' of a foresight exercise and about the distribution of 'probability' of the outcomes. We follow Stirling and Scoones (2009, Fig. 2) and refer to four different states reflecting combinations of assuming highly problematic or non-problematic knowledge about 'outcomes' and 'probabilities'. First, 'Risk-based Expectations': when the analyst assumes that she has reliable knowledge of the relevant outcome, on the distribution of possible instances of the outcome and on the value of each instance. An example here would be Moore's Law: the analyst knows that the relevant outcome is a continuous increase in the number of transistors on integrated circuits (doubling speed of processors, memory, etc), and she assumes that she can predict change in the size of microprocessors in the near future. Second, 'Uncertainty': the analyst can assume knowledge on the outcome, - i.e. she assumes perfect knowledge of the outcome she wants to assess, but she has no knowledge of the probability distribution of its occurrences - she cannot assign 
probabilities to outcomes (and therefore no expected value). Take the example of a flood: an analyst cannot predict it, although it is well defined as a negative phenomenon. Third, 'Ambiguity': the analyst can assume some knowledge on the probabilities and the final distribution of events, but she does not know what is the relative desirability of the various outcome, or how to evaluate them. Fourth, 'Ignorance': we lack knowledge on both the probabilities of the different events and how to evaluate them. In other words, anything might happen. For example, we do not know neither the likelihood nor the type of consequences in the event of beings from another planet visiting planet earth. For a more detailed discussion on the representation of knowledge in FTA exercises we refer the reader to an article focused specifically on this issue (Ciarli et al., 2013b).

In the Ciarli et al (2013a, Sec. 3.2) we briefly review the selected ten families of techniques, and discuss their strengths (pros) and weaknesses (cons), their most common applications (contexts), and the organisations that are more likely to use or to take advantage of them - e.g. national governments, industries, companies, non-governmental organisations and international organisations.

\subsection{Classification, use and characteristics of FTA techniques}

As in earlier classifications of FTA techniques, it is important to remember that the combination of two or more techniques under the same family is intended to facilitate the reader's orientation and choice among a large number of different techniques. However, the boundaries among families should not be taken as rigid. As we will see, the same technique can fall into more than one group depending on how it is used. Also, if we enter the different types of FTA activities, we can apply different classifications. For example, particularly in the context of foresight, different techniques may be better suited to different phases in the foresight exercise (Saritas, 2006; Saritas and Aylen, 2010), and a foresight activity will usually combine more than one technique.

In Table 1 we distribute techniques according to the ten families listed above and their main use; in Table 2 we summarise the characteristics of each family, including how they represent knowledge about 'outcomes' and knowledge about the 'probability' of occurrence of events. In both tables the heading represents how the techniques tend to be used. Ciarli et al (2013a, Sec. 3.2) reviews the techniques within each of the ten families, explains why techniques are clustered together, and discuss the main characteristics, uses, knowledge about outcomes and probabilities, and the main advantages and disadvantages in different contexts. The description is also accompanied by a list of basic reference from the literature. See Ciarli et al (2013a, Sec 
3.2). Here we provide a very quick summary of the ten families, moving from left to right in tables 1 and 2.

The 'creative' family includes techniques such as Theory of Inventive Problem Solving or TRIZ. These are mainly descriptive, extrapolative and imaginative techniques, which are applied to a wide range of problems (whether well-known or relatively unknown).

Monitoring and intelligence techniques include techniques such as Bibliometrics, Conjoint Analysis, Webometrics, (Social Software) and Social Network Analysis (SNA). The last two are new to FTA and we rely more on their applications in practice than on reviews in the literature. These techniques are used mainly to gather information from individuals on their preference, relations, attributes, etc. These are data gathering techniques, extrapolative, and close to foresight methods. 


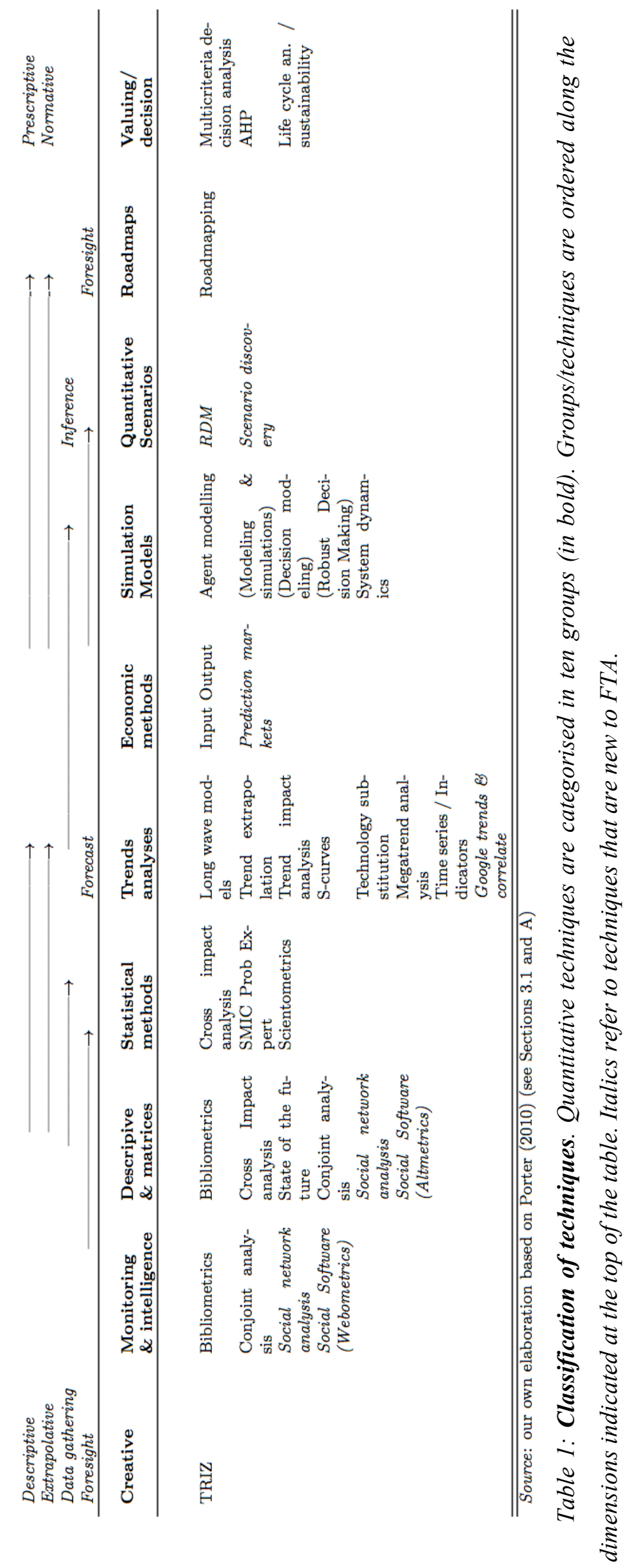


The Descriptive and Matrices family includes techniques which are in a mid ground between pure monitoring and pure statistical methods, and include Scientometrics (Bibliometrics and Patent Analysis), Cross-Impact Analysis (CIA), State of the Future Index (SOFI), SNA, Social Software such as Webometrics and Altmetrics, and Conjoint Analysis. We refer to these techniques as data gathering and extrapolative techniques, structured (some more than others) in statistical indicators. Most of them are used as a complement to other more forward looking FTA techniques. The main features of Social Software techniques is that they broaden out the sources of information and knowledge, looking into internet related media. Most of the techniques pertaining to this family are then still data gathering and extrapolative techniques, structured (some more than others) in statistical indicators.

All statistical method techniques are data gathering and extrapolative. We distinguish between techniques that gather secondary data from large data bases -Bibliometrics and Patent analysis mentioned above - from those that gather data from experts such as CIA. All these techniques are closer to foresight than to forecasting, and recent use of Big Data can be seen as a huge expansions in the involvement of different sources of information.

With the next family, trend analyses, we move from data gathering to inference oriented techniques, which are more useful for forecasting than for foresight exercises. However, these techniques are still more useful for extrapolative (rather than normative) exercises and are more descriptive than prescriptive. There are a large number of techniques used for trend analyses, ranging from Indicators/Time Series Analysis (I/TSA) and Trend Extrapolation, to Long Wave Analysis/Models (LWA) and Megatrends Analysis, and now including more recent 'nowcasting' techniques such as Google Trends and Google Correlate. The latter is also based on Big Data, and exploits very simple behaviour among Internet users, the search for solutions to specific problems on the internet using Google.

Economic methods take a further step into forecasting, mainly with Input Output analysis and prediction markets. Input Output models are mainly used to construct inferences from available data with respect to income growth, structural change and their environmental impact. They are mainly descriptive (projecting scenarios), and are both extrapolative and normative when, as it is usually the case, the assumptions underlying the modelling are based on normative positions. Included among the new techniques for FTA, prediction markets are used for more specific and short term estimates of the probability of a specific event. As many new techniques they broaden out the source of information to a broad set of agents.

A number of modelling methods are better suited to deal with complex dynamics than the economic methods just seen. Complexity is acknowledged as a source of potential ignorance that 
needs to be accounted for when considering possible future dynamics (or scenarios). These methods include System Dynamics and a number of methods and tools that have nurtured Agent Modelling - such as Cellular Automata, Chaotic Systems and Agent-based Computational Economics (ACE). These models are descriptive as much as prescriptive in relation to defining assumptions, variables, parameters and the system represented. They serve both extrapolative and normative purposes and, in some cases, are used as tools to build scenarios, i.e. to understand the system analysed, and in other cases to forecasting. They are also useful as inference exercises, sometimes using data gathered elsewhere.

The techniques clustered in the next family, quantitative scenarios, use similar methods but are more focused on the discovery and analysis of future scenarios. Quantitative scenarios are built using a number of techniques that allow evaluation of the probability of different events occurring in the future, and the outcomes attached to those events. The development of scenarios retains an element of foresight, whereas the construction of different future outcomes to inform policy options is closer to forecasting. Quantitative based scenarios use large amounts of data and generate inference. Here, we refer mainly to those techniques that use agent modelling and statistical methods to evaluate long term policy options, such as the recently developed Robust Decision Modelling (RDM) and Scenario Discovery.

Technology roadmapping is an umbrella term used to describe a group of (quantitative and qualitative) techniques that help to plan and co-ordinate S\&T development at various levels. A roadmap is a layout of relationships that are perceived as desirable and expected to occur between science, techniques and products over time, in the process of a technology achieving practical application and/or reaching the market. While roadmapping techniques are sometimes employed for forecasting, they mainly serve to collect and construct shared views on S\&T development, in line with foresight methods. While quantitative roadmapping exercises use data gathered with other quantitative techniques, they are more prescriptive than descriptive, and more normative - based on data extrapolation- rather than being extrapolative.

The techniques identified in the group of valuing and decision making serve mainly prescriptive functions, enabling policy-makers' decisions about desired future outcomes. This implies that these techniques are highly normative. To be able to assess different outcomes these techniques make use of the information collected using more extrapolative techniques. Among the techniques included in this family are Multicriteria Decision Analysis, including Analytical Hierarchy Process and Life Cycle/Sustainability Analysis (LCA).

Summing up, techniques at the left hand side of Table 1 are mainly used for data gathering, or to describe statistical properties from very different data sources: understanding the past, to imagine the future (in some cases). Techniques belonging to families on the right hand side of 
Table 1, instead, tend to be used to make inferences or to aim to find optimal solutions: influencing the future. Accordingly, techniques listed under families positioned at the two ends of Table 1 are mainly used for foresight activities; while those techniques listed in the centre of the Table are more commonly used for forecasting exercises.

We next move to discussing some regularities with respect to the characteristics of the different families of techniques, related to their position in the tables with respect to the main uses of the techniques.

\subsection{Regularities on the characteristics of FTA techniques}

If we move from left to the right of Table 2 a few more regularities emerge with respect to number of uses and characteristics of the techniques.

\section{Drivers: non-specific versus specific context}

First, most techniques, from creative to the trends analysis, are used in FTA activities focused on science, technology and innovation without necessarily engaging with their contexts. As we move from techniques within the economic methods class towards the right hand side of Table 2 most of the techniques are used in FTA activities driven by specific contexts. These contexts can range from evaluation of the environmental impact of economic activities (Input-Output analysis, I/O), likelihood of a specific event occurring, e.g. an election, political instability, a natural disaster (Prediction Markets), applications in operational research (System Dynamics), water management (Robust Decision Making), key technologies (Analytical hierarchy process), and so on. 


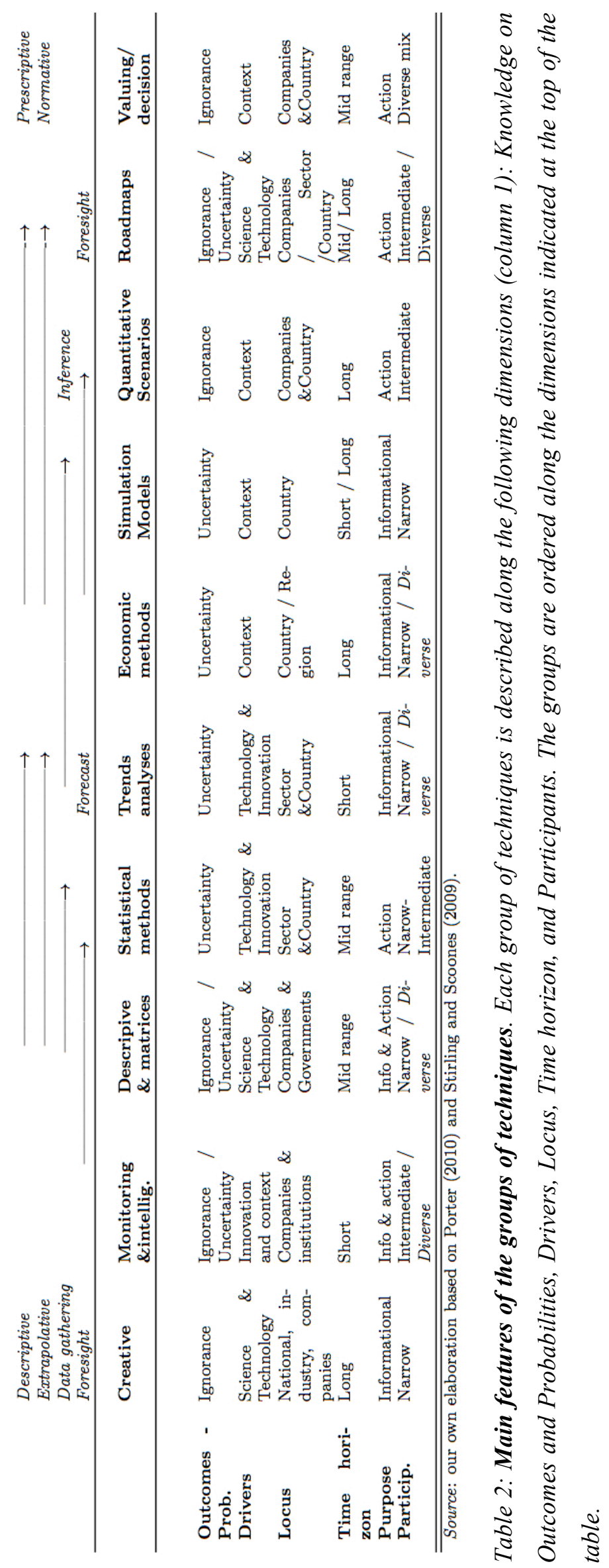




\section{Time horizon: short versus long}

Second, the techniques included in the classes at the left side of Table 2 tend to be more suited to studying short to medium-term time horizons; those in classes towards the right hand side of Table 2 apply to the study of longer time horizons. In general, this reflects the fact that forecasting activities tend to consider a shorter time horizon than foresight activities. However, there are also differences among foresight and forecasting oriented techniques. For example, most Trend Analyses we know of have rather short time horizons, while Simulation Models usually seek to provide insights over a long time horizon (although both can be extrapolated as long-term as the practitioner wants). Among quantitative foresight techniques, Roadmaps tend to apply to more distant future techniques listed under Monitoring and Description, i.e. Conjoint Analysis and Cross Impact Analysis. As we discuss in more detail in (Ciarli et al., 2013b) this difference is related also to the assumptions required for different techniques about the knowledge on outcomes and probabilities of events. When the time horizon used by the analyst is shorter, the knowledge about outcomes and probabilities is more likely to be perceived as fairly unproblematic. .

\section{Purpose: information versus action}

Third, following from the ordering of the classes according to the data gathering / inference continuum, i.e. from descriptive to prescriptive, techniques classified on the left hand side of Table 2 are used more for informational purposes than for defining action (although a few techniques set the stage to design actions in subsequent steps). As we move towards the right hand side of Table 2 - scenarios, roadmaps and valuing/decision making classes - techniques are more likely to be used to implement specific actions. As discussed in the previous Section, Monitoring, Descriptive and Statistical methods families of techniques serve the purpose of collecting and systematising information, which may inform future analysis or action. On the other hand, techniques such as Roadmaps are employed explicitly to define common visions and standards for future technological developments. Similarly, scenario exercises are developed for very specific contexts and issues, where policy makers or large corporations want to identify potential solutions to problems. The decision-making feature is related to another characteristic that seems to indicate a rather regular pattern, i.e. context specificity. On average, techniques on the right end side of Table 2 are more context specific than those on the left hand side.

\section{Participation: Opening-up the inclusion of stakeholders' views}

Fourth, we consider the extent of inclusion ('participation') of various stakeholders views, in the broad understanding of participation used in this paper, i.e. in the sense of gathering a plurality 
of perspectives not collected by other quantitative, data intensive techniques. If we exclude the techniques new to FTA, we can identify a pattern, moving from classes of descriptive techniques to classes of prescriptive techniques. In the former, the participation of stakeholders is inexistent or mostly narrow, with a few exceptions such as Conjoint Analysis and Cross Impact Analysis which require an intermediate level of participation. This applies also to some techniques that require advanced technical training and understanding of the techniques. The last three families on the right hand side of Table 2, involve a wider mix of stakeholders taking part in the decision process. This may be related to the stronger prescriptive nature of these techniques, which are aimed more at context specific issues rather than at general science and technology studies. If, instead, we include techniques that are new to FTA, the picture changes with most classes on the descriptive side featuring techniques aimed at collecting information/opinions from a quite large and diverse number of passive stakeholders and/or subjects. In Ciarli et al. (2013b) we discuss how the 'broadening out' of the acquisition of information by some of the new techniques differs substantially from the broad participation that characterises foresight activities. This broadening allows us to capture the views of much bigger constituencies (thousands of individuals), but a major caveat is that their participation is generally passive - and preferences revealed by indirect choices may not be in agreement with explicitly voiced preferences. In other words, new techniques based on Big data simply add richness in the information, maybe by revealing (apparent) preferences of people, but perform much worse with respect to decisionmaking than more prescriptive techniques (last three families on the right in Table 2). Overall, none of the quantitative techniques surveyed suggest a level of inclusion of stakeholder's opinion that is desirable for discussing the direction of future technologies that may have huge impact on people's life and the distribution of wealth.

\section{Locus: use of different techniques across different organisations}

Fifth, we were unable to identify a pattern related to the types of organisations that use the techniques categorised. Companies and governments tend to use different techniques, but for reasons that lie in a number of features that are not captured by the ordering of our classification. For example, companies tend to prefer more context-specific and action-oriented techniques, and those that are most useful in relatively short time horizons. Instead, broad participation is required for certain FTA activities by both firms and governments, and narrow participation for others. A mapping of (classes of) techniques with respect to (types of) organisations would require a sharper, more fine-grained focus on both techniques and organisations and few studies provide such information. See e.g. Popper (2008b) and more generally the EFNM Dynamo project. 


\section{Knowledge about outcomes and probabilities}

Finally, the descriptive classes of techniques (left) are used mainly under conditions of uncertainty, in which the analysis focus only on certain outcomes (i.e. knowledge about outcomes is assumed to be unproblematic), but wish to improve the knowledge about outcomes' realisation (because knowledge about probabilities is problematic). On the other hand, prescriptive classes (right) are used mainly under conditions of ignorance, where the analyst assumes neither outcomes nor their likelihoods (knowledge about both outcomes and probabilities is problematic). This important difference is discussed in detail in Ciarli et al. (2013b).

\section{Conclusions}

Technical change and the emergence and diffusion of new technologies are having increasing impacts on the economy and society. FTA can help us reflect on the likely directions of technologies, manage the risks involved and shape technological trajectories in order to improve the long term benefits to society. However, can we choose among the many different FTA to use when faced with the possibility of conducting a foresight? In this paper we surveyed the large (and growing) number of quantitative techniques designed to help our understanding of and thinking about future technologies. The paper makes two key contributions to the literature. First, we provide policy makers with a more digestible understanding of different quantitative techniques that can be used in FTA, discussing at the same time their limit, and their main advantage. Second, we explored regularities among the techniques with respect to drivers, time horizon, purpose, participation (especially with respect to Big data), locus, and knowledge about outcomes and probabilities.

We found that FTA quantitative techniques are extremely diverse, and that the choice of FTA techniques appropriate for a given foresight exercise depends on the purpose and characteristics of specific analysis. Hence, the quality of an FTA does not depend on an 'ideal' or intrinsic quality of the FTA technique itself, but rather on achieving a satisfactory alignment between the goals of the foresight exercise and the particular FTA technique that will fulfil them.

In order to help in the selection of an appropriate FTA technique, we classified techniques into classes with common characteristics. Adapting a classification suggested by Porter (2010), we ordered the FTA quantitative techniques into ten families. We briefly summarised the main uses of techniques, referring the interested reader to a more complete discussion on the main features of these classes, including the main advantages (pros) and disadvantages (cons) of the different classes of techniques, in which contexts (drivers) they were applied more often and by 
which types of organisation (locus) in Ciarli et al (2013a, Sec 3.2). We investigated whether there is any regularity across classes with respect to time horizon, main purposes (leading to acquisition of information or actions) and the number of different stakeholders involved. To do so, we ordered the families of techniques according to whether they are mainly descriptive and extrapolative (not necessarily extrapolating from time series) or mainly prescriptive and normative (from left to right in Tables 1 and 2). This distinction also reflects the main use (purpose) of each technique, and in which stage of the FTA exercise it is most helpful.

Techniques at the left hand side of Table 1 are mainly used for data gathering (extrapolating and describing available information from a number of different sources including stakeholders, the World Wide Web, patents, publications, people's perceptions and choices, etc.). If the data are analysed using descriptive/extrapolative techniques, the analysis is purely descriptive. In other words these techniques are used to describe observed statistical properties based on information collected in various forms and from a variety of sources. The techniques on the right hand side of Table 1 tend to be used to make inferences or to aim to find 'optimal' solutions for the future, based on elaboration of the information gathered. These techniques are used to analyse possible future outcomes, establish and define knowledge about the future, and purposefully shape it. Knowledge about the future is established by defining desired outcomes and the probability of the occurrence of different instances of these outcomes.

The uses of the techniques along the left-right dimension are related to the type of FTA exercise. Techniques at the extreme ends of the classification (left and right in Tables 1 and 2) are mainly used for foresight activities, while those in the centre of the scheme are more commonly used for forecasting. We can differentiate also among the time horizons of foresight activities: those that use techniques at the left hand side in Tables 1 and 2 are aimed at understanding the past; those using techniques on the right hand side are aimed at influencing the future.

The classification we proposed in this paper thus is relevant for policy makers making choices on FTA because it may help reflect on the different uses discussed - DescriptivePrescriptive, Extrapolative-Normative, Data gathering-Inference and Foresight-Forecasting, and their characteristics - Drivers, Locus, Time horizon, Purpose, Participation and assumed incompleteness of knowledge about outcomes and probabilities (uncertainty), provide useful information on the advantages and disadvantages of some techniques with respect to others, for different FTA activities. However, these dimensions only partially define the advantages of different techniques. Indeed, these techniques are also performative: first, their use affects the knowledge that is crafted by the analyst with respect to the probability of the different events and evaluation of their corresponding outcomes. Second, different (classes of) techniques 
involve a number of assumptions about probabilities and their outcomes (e.g. statistical properties, behavioural assumptions in modelling). Third, in many cases techniques are employed to reduce perceived incompleteness of knowledge about outcomes and their probabilities.

To what extent do the techniques broaden or restrict the initial sources of information used (see also the characterisation of classes in terms of participation)? And, to what extent do the techniques allow the analyst and the policy maker to evaluate alternative (closure) options? We found little about some of the newest techniques in relation to what they add to the standard techniques, and what instruments they provide analysts and policy makers, to 'open up' alternative outcomes. To investigate this issue in detail, in Ciarli et al. (2013b), we evaluate the contribution of these quantitative techniques, referring to the Stirling and Scoones (2009) framework to highlight the contributions made by these techniques to 'opening up' to increase the number of options to be considered, or 'closing down' to narrow the focus to a smaller number of more likely outcomes. 


\section{References}

Aaltonen, Mika and T. Irene Sanders, "Identifying systems' new initial conditions as influence points for the future," Foresight, 2006, 8 (3), 28 - 35.

Armstrong, J. Scott, "How to Make Better Forecasts and Decisions: Avoid Face-to-Face Meetings," FORESIGHT: The International Journal of Applied Forecasting, 2006, Fall (5), 3-15.

Arthur, W.B., "Competing technologies, increasing returns and lock-in by historical events," Economic Journal, 1989, 99, 116-131.

Bishop, Peter, Andy Hines, and Terry Collins, "The current state of scenario development: an overview of techniques," Foresight - The journal of future studies, strategic thinking and policy, 2007, 9 (1), 5-25.

Boden, Mark, Ron Johnston, and Fabiana Scapolo, "The role of FTA in responding to grand challenges: A new approach for STI policy?," Science and Public Policy, 2012, 39 (2), $135-139$.

Cachia, Romina, Ramón Companó, and Olivier Da Costa, "Grasping the potential of online social networks for foresight," Technological Forecasting and Social Change, 2007, 74 (8), $1179-1203$.

Ciarli, Tommaso, Alex Coad, and Ismael Rafols, "Quantitative Analysis of Technology Futures. Part I: Techniques, Contexts, and Organisations", Nesta Working Paper 13/08, Nesta, London May 2013a.

Ciarli, Tommaso, Alex Coad, and Ismael Rafols, "Quantitative Analysis of Technology Futures, Part II: Conceptual framework for positioning FTA techniques in policy appraisal," Nesta Working Paper 13/09, Nesta, London May $2013 \mathrm{~b}$.

Coates, J.F., "Foresight in Federal government policy making," Futures Research Quarterly, 1985, 1 (2), 29-53.

Cowan, Robin and Philip Gunby, "Sprayed to Death: Path Dependence, Lock-in and Pest Control Strategies," The Economic Journal, May 1996, 106 (436), 521-542.

Cuhls, Kerstin, "From Forecasting to Foresight Processes? New Participative Foresight Activities in Germany." Journal of Forecasting, 2003, 22(2-3): 93-111.

Cuhls, Kerstin. Methoden Der Technikvorausschau - Eine Internationale Übersicht. Stuttgart: Fraunhofer IRB Verlag, 2008.

David, Paul A., "Clio and the Economics of QWERTY," The American Economic Review, 1985, 75 (2), 332-337.

Diamond, Jared, Guns, Germs, and Steel, W. W. Norton, 1997. 
Eerola, A. and I. Miles, "Methods and tools contributing to FTA: A knowledge-based perspective," Futures, 2011, 43 (3), 265 - 278.

Ely, Adrian, Nicola Grassano, Michael Hopkins, Nelson Mojarro, Tammy-Ann Sharp, Annie Wilkinson, James Wilsdon, and Go Yoshizawa, "Technology Foresight for Developmental States: A comparative analysis," Project Report, SPRU, University of Sussex, Brighton 2012.

Fontela, Emilio, "Leontief and the Future of the World Economy," Working Paper, Universidad Autónoma de Madrid, Instituto L.R.Klein undated.

Forrester, J.W, World Dynamics, Cambridge, MA: Wright-Allen Press, 1971.

Franzen, Jonathan, Freedom, New York: Farrar, Straus and Giroux, 2010.

Georghiou, Luke and Michael Keenan, "Evaluation and Impact of Foresight," in Luke Georghiou, Jennifer Cassingena Harper, Michael Keenan, Ian Miles, and Rafael Popper, eds., The Handbook of Technology Foresight: Concepts and Practice, Edward Elgar, 2008, chapter 16, pp. 377-399.

Glenn, Jerome C. and Theodore J. Gordon, eds, Futures Research Methodology Version 2.0, Millennium Project of the American Council for the United Nations University, 2003.

Glenn, Jerome C. and Theodore J. Gordon, eds, Futures Research Methodology Version 3.0, The Millennium Project, 2009.

Graefe, Andreas and J. Scott Armstrong, "Comparing face-to-face meetings, nominal groups, Delphi and prediction markets on an estimation task," International Journal of Forecasting, 2011, 27 (1), 183 - 195.

Grupp, Hariolf, and Harold A Linstone. "National Technology Foresight Activities Around the Globe." Technological Forecasting and Social Change, 1999, 60 (1), 85-94.

Horton, Averil, “A simple guide to sucessful foresight," Foresight, 1999, 1 (1), 5-9.

Irvine, John and Ben R. Martin, Foresight in science: picking the winners, London: Dover Frances Pinter, 1984.

Jackson, Michael, "Methods," in Michael Jackson, ed., Practical Foresight Guide, Shaping Tomorrow, 2011, chapter 3. Last revised: 14.01.11.

Johnston, R., "Historical Review of the Development of Future-Oriented Technology Analysis," in Cristiano Cagnin, Michael Keenan, Ron Johnston, Fabiana Scapolo, and Rémi Barré, eds., Future-Oriented Technology Analysis, Springer Berlin Heidelberg, 2008, pp. $17-23$.

Kahn, H. and A.J. Wiener, The year 2000: a framework for speculation on the next thirty-three years, New York: Macmillan, 1967. 
Keenan, Michael, Dan Abbott, Fabiana Scapolo, and Mario Zappacosta. Mapping Foresight Competence in Europe: The EUROFORE Pilot Project. IPTS Technical Report Series. 2003

Lempert, Robert, Steven Popper, and Steve Bankes, "Robust Decisionmaking," in Jerome C. Glenn and Theodore J. Gordon, eds., Futures Research Methodology Version 3.0, The Millennium Project, 2009, chapter 22.

MacKenzie, Donald, "Economic and Sociological explanations of Technological Change," in “Knowing machines: essays on technical change,” MIT Press, July 1998, pp. 49-65.

Magruk, Andrzej, "Innovative classification of technology foresight methods," Technological and Economic Development of Economy, 2011, 17 (4), 700-715.

Martin, Ben R., "Foresight in science and technology," Technology Analysis \& Strategic Management, 1995, 7 (2), 139-168.

Martin, Ben R., "The origins of the concept of "foresight" in science and technology: An insider's perspective," Technological Forecasting and Social Change, 2010, 77 (9), 1438 1447.

Martin, Ben R. and John Irvine, Research foresight: priority-setting in science, London: Pinter Publishers, 1989.

Meadows, Donella H., Dennis L. Meadows, Jorgen Randers, and William W. Behrens III, The Limits to Growth, Universe Books, 1972.

Miles, Ian, "Appraisal of Alternative Methods and Procedures for Producing Regional Foresight," Report prepared by CRIC for the European Commission's DG Research funded STRATA - ETAN Expert Group Action, CRIC, Manchester 2002.

Miles, Ian, "The development of technology foresight: A review," Technological Forecasting and Social Change, 2010, 77 (9), 1448 - 1456.

Miles, Ian, Jennifer Cassingena Harper, Luke Georghiou, Michael Keenan, and Rafael Popper, "The Many Faces of Foresight," in Luke Georghiou, Jennifer Cassingena Harper, Michael Keenan, Ian Miles, and Rafael Popper, eds., The Handbook of Technology Foresight: Concepts and Practice, Edward Elgar, 2008a, chapter 1, pp. 3-23.

Miles, Ian, Jennifer Cassingena Harper, Luke Georghiou, Michael Keenan, and Rafael Popper, "New Frontiers: Emerging Foresight," in Luke Georghiou, Jennifer Cassingena Harper, Michael Keenan, Ian Miles, and Rafael Popper, eds., The Handbook of Technology Foresight: Concepts and Practice, Edward Elgar, 2008b, chapter 17, pp. 400-417.

Nugroho, Yanuar and Ozcan Saritas, "Incorporating network perspectives in foresight: a methodological proposal," Foresight : the Journal of Futures Studies, Strategic Thinking and Policy, 2009, 11 (6), 21-41. 
Pang, Alex Soojung-Kim, "Futures 2.0: rethinking the discipline," Foresight - The journal of future studies, strategic thinking and policy, 2010, 12 (1), 5-20.

Pinch, Trevor J. and Wiebe E. Bijker, "The Social Construction of Facts and Artefacts: or How the Sociology of Science and the Sociology of Technology might Benefit Each Other," Social Studies of Science, 1984, 14 (3), 399-441.

Popper, Rafael, "Foresight Methodology," in Luke Georghiou, Jennifer Cassingena Harper, Michael Keenan, Ian Miles, and Rafael Popper, eds., The Handbook of Technology Foresight: Concepts and Practice, Edward Elgar, 2008a, chapter 3, pp. 44-87.

Popper, Rafael, "How are foresight methods selected?," Foresight - The journal of future studies, strategic thinking and policy, 2008b, 10 (6), 62-89.

Porter, Alan L., "Future-oriented Technology Analyses: The Literature and Its Disciplines," in Patrick Van Der Duin, ed., Knowing Tomorrow?: How Science Deals With the Future, Eburon Academic Publishers, 2007, chapter 11, pp. 183-201.

Porter, Alan L., "Technology foresight: types and methods," International Journal of Foresight and Innovation Policy, 2010, 6 (1-3), 36-45.

Porter, Alan L., W. Bradford Ashton, Guenter Clar nad Joseph F. Coates, Kerstin Cuhls, Scott W. Cunningham, Ken Ducatel, Patrick van der Duin, Luke Georgehiou, Theodore Gordon, Harold Linstone, Vincent Marchau, Gilda Massari, Ian Miles, Mary Mogee, Ahti Salo, Fabiana Scapolo, Ruud Smits, and Wil Thissen, "Technology futures analysis: Toward integration of the field and new methods," Technological Forecasting \& Social Change, 2004, 71, 287-303.

Rip, A., J. W Schot, and T. J Misa, eds, Managing Technology in Society. The Approach of Constructive Technology Assessment, London: Pinter Publishers, 1995.

Robinson, Douglas K.R., Lu Huang, Ying Guo, and Alan L. Porter, "Forecasting Innovation Pathways (FIP) for new and emerging science and technologies," Technological Forecasting and Social Change, 2011, 80 (2), 267-285.

Saritas, Ozcan, "Systems Thinking for Foresight." Phd thesis, Manchester Institute of Innovation Research, University of Manchester 2006.

Saritas, Ozcan and Jonathan Aylen, "Using scenarios for roadmapping: The case of clean production," Technological Forecasting and Social Change, 2010, 77 (7), 1061 - 1075.

Scapolo, Fabiana and Ian Miles, "Eliciting experts' knowledge: A comparison of two methods," Technological Forecasting and Social Change, 2006, 73 (6), 679 - 704.

Stirling, A. C. and I. Scoones, "From risk assessment to knowledge mapping: science, precaution and participation in disease ecology," Ecology and Society, 2009, 14 (2). 
Warden, C., "An application of some knowledge management concepts in foresight," Training Programme on Technology Foresight 1, UNIDO Regional Initiative on Technology Foresight for Central and Eastern Europe and the Newly Independent State, Gebze, Turkey, 19-23 November 2007.

Wilting, Harry C., Albert Faber, and Annemarth M. Idenburg, "Investigating new technologies in a scenario context: description and application of an input-output method," Journal of Cleaner Production, 2008, 16 (1, Supplement 1), S102 - S112.

Wolfers, Justin and Eric Zitzewitz, "Prediction Markets," in Jerome C. Glenn and Theodore J. Gordon, eds., Futures Research Methodology Version 3.0, The Millennium Project, 2009. 


\section{A List of reviewed techniques}

The 26 main techniques initially selected were:

- Agent modelling (including Complex adaptive systems, Modelling and simulations, Robust Decision Making, and Decision modelling)

- Analytical hierarchy process (AHP)

- Bibliometrics (including Scientometrics, Research profiling, patents, and tech mining)

- Conjoint analysis

- Content analysis

- Cross impact analysis

- Force field analysis

- Indicator/Time Series Analysis

- Input Output Analysis

- Key technologies

- Long Wave analysis

- Megatrend analysis

- Multicriteria decision analysis (including data envelopment analysis and other methods),

- Roadmapping

- S-Curves

- SMIC Prob expert

- Social Network Analysis

- State of the future index (SOFI)

- Structural Analysis

- Sustainability analysis (life cycle)

- Systems simulations (including system dynamics and KSIM)

- Technology substitution

- Trend extrapolation 
- Trend impact analysis

- TRIZ

- Webometrics

Other 11 less relevant techniques non selected in the initial sample were:

- Classification trees

- Critical Influence analysis

- Diffusion modeling

- Markov

- Precursor analysis

- Probability trees

- Regression analysis

- Requirement analysis (needs analysis, attribute X tech matrix)

- Rule based forecast

- Statistical analysis

- Stochastic forecast 